\title{
A FRAMEWORK FOR THE ACTIVE MANAGEMENT OF A GLOBAL CURRENCY FUND
}

\author{
Antonio Marcos Duarte Júnior*
}

\begin{abstract}
We consider the problem of optimally managing an investment fund by taking positions in spot and derivatives foreign exchange markets. The framework proposed combines scenario analysis and downside risk to provide an optimization model more realistic and conceptually superior when compared to previous currency works based on the Markowitz's Mean-Variance framework. A historical simulation covering three years, and involving eleven currencies, is presented to illustrate the potential of the framework. Extensions to cover multiperiod investment analysis are also discussed.
\end{abstract}

\section{Resumo}

Consideramos o problema de administrar um fundo de investimentos no mercado de câmbio mundial. A nossa proposta combina análise de cenários e medidas assimétricas de risco de forma a obter um modelo de otimização mais realista e conceitualmente superior quando comparado a trabalhos anteriores que se basearam na análise Média-Variância de Markowitz. Uma simulação histórica cobrindo três anos, e envolvendo onze moedas, é apresentada para ilustrar o potencial da metodologia. Extensōes para investimentos multi-periodo são fornecidas também.

Key words: Downside risk; foreign exchange; portfolio management; scenario analysis.

JEL Code: C15, C61, F31 e G11.

* Banco Pactual S.A., Rio de Janeiro, Brasil.

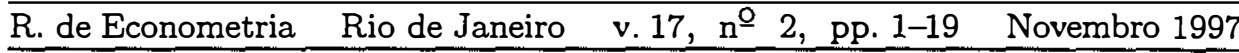


A Framework for the Active Management of a Global Currency Fund

\section{Introduction.}

Currency risk is a measure of the potential losses of a portfolio due to changes in the relative value of securities in different currencies. Currency risk can be managed by hedging a position. Two closely related problems on currency hedging are those of optimal currency hedge (Glen \& Jorion (1993), Sorensen et al (1993)) and currency overlays (Braccia (1995) and Jorion (1994)).

Another currency problem is that of actively managing a global currency fund. This problem is about the optimal management of investment funds by taking long and/or short positions only in spot and derivatives foreign exchange markets. Our objective in this work is to propose a framework for the active management of a global currency fund.

In terms of its organization this work considers in the next four sections general modeling questions related to the currency allocation problem. The results of a historical simulation are presented, and extensions to multiperiod investment problems discussed.

\section{Problems with the Mean-Variance Framework.}

One characteristic of all currency hedging methodologies proposed so far is that they are based on the Markowitz's Mean-Variance (MV) framework. The modeling weaknesses of the MV framework have already been well discussed and documented for general asset allocation problems (Chopra (1993) and Michaud (1989)), as well as in the particular case of currency hedging (Gardner \& Wuilloud (1995)). More recently, practitioners involved with the development of methodologies for fund management deviated from the MV framework, preferring instead to rely on the principles of an emerging field in operations research: stochastic programming (Nemhauser et al (1989)). Solving stochastic programs in financial applications can be done very efficiently using scenario analysis (see Carino et al (1994) for a state-of-the-art example). 
We follow this recent trend. In this work we propose a methodology for the management of a global currency fund that relies on scenario analysis and downside risk (Harlow (1993) and Sortino \& Van der Meer (1991)), instead of the MV framework. Some of the distinctive features of this proposal are:

1) While the MV framework consolidates all scenarios in a singlepoint forecast of expected returns, this proposal obtains the optimal currency allocation considering the expected return for each scenario separately. There are several advantages when using this modeling approach, such as a clearer picture of possible profits/losses for the optimal currency allocation selected. Another advantage is that while the MV framework never obtains optimal allocations with negative expected returns, ${ }^{1}$ what is unrealistic, this methodology reports under which scenarios the optimal currency allocation presents positive returns, as well as under which scenarios the optimal currency allocation presents negative returns.

2) The statistical distributions of returns and utility functions that characterize the MV framework have been documented in the finance literature (Chamberlain (1983), Epstein (1985), Huang \& Litzemberger (1988) and Kallberg \& Ziemba (1983)). The proposal presented in this work does not require any assumption about the underlying distribution of returns. It can use any utility function as the objective function for maximization. The framework proposed can incorporate, for example, scenarios generated in risk measurement models based on the Monte Carlo or the historical simulation approaches. Also, this proposal handles instruments with an asymmetric distribution of returns ${ }^{2}$ more conveniently than MV-based approaches (Duarte (1994),

\footnotetext{
${ }^{1}$ Assuming that a riskfree asset is available for investing all the funds.

2 Such as options, bonds with embedded options, mortgage-backed securities, etc.
} 
A Framework for the Active Management of a Global Currency Fund

Duarte (1997), Harlow (1993), Lewis (1990) and Marmer \& Ng (1993)). Finally, it can be verified that for certain modeling hypotheses, the framework proposed in this work can capture the MV framework as a particular case.

3) A single-point forecast is known not to be appropriate when trying to anticipate a move in any particular market, specially when such a move is a rare event (Koskosidis \& Duarte (1997)). Another advantage of scenario analysis is that it handles very easily multiple forecasts, allowing the user to "stress test" a portfolio while searching for the optimal asset allocation. Moreover, scenario analysis allows a more flexible approach for currency allocation modeling because it allows the impact of worst case scenarios to be tracked during the optimization phase of currency allocation, and the losses under these circumstances to be required not to violate a maximum acceptable loss.

4) Instead of relying on a single-point forecast of a covariance matrix for measuring risk, this proposal uses different utility functions to capture the investor's risk profile over a larger range of possible returns, let these be profits or losses. The use of different utility functions has already been well documented in the asset allocation literature (Kallberg \& Ziemba (1983)).

5) The concept of Minimum Acceptable Return (MAR), which is usually associated with downside risk, is incorporated in the currency allocation process. The MAR is an investor-dependent quantity that measures the minimum level of return that would satisfy the needs of a particular investor for a investment horizon. By explicitly incorporating the MAR, this proposal can be easily tailored for the particular needs of this investor, resulting in a more realistic and useful approach. Moreover, numerical results reported in Duarte (1994) show that the use of downside risk as the risk measure in asset allocation models proved to be 
superior than the use of the standard deviation (i.e., the MV framework) in the US equity and fixed income markets during a period of twenty years. Similar conclusions were reported in Harlow (1993).

\section{A Graphical Analysis of Currency Allocation.}

Our proposal to the problem of currency allocation can be easily visualized by graphical representations such as networks, as originally proposed by Crum et al(1979) in another context. We present the basics of our approach for currency allocation using the very simple example given in Figure 1. It considers only two foreign currencies for investment (Australian dollar, AUD, and Belgian franc, $\mathrm{BEF}$ ), uses the US dollar (USD) as the base currency, ${ }^{3}$ and does not allow leverage or multiperiod investments. Extensions to multiperiod currency allocation will be considered later.

Figure 1

A network for currency allocation

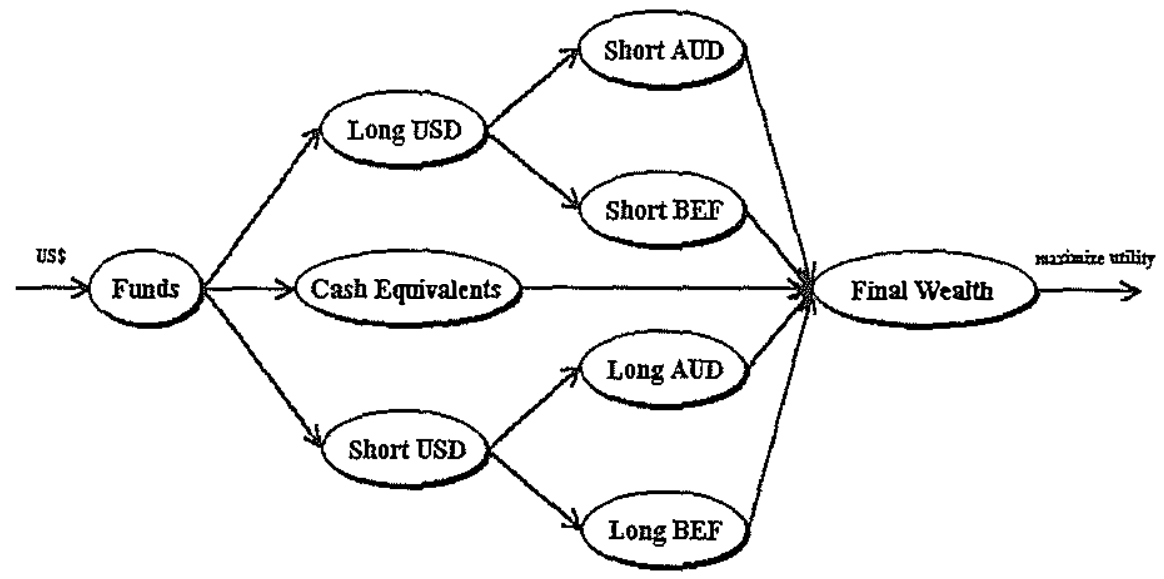

${ }^{3}$ That is, all returns and risks (expected and realized) will be measured in USD. 
The simplest way to visualize the currency allocation process using Figure 1 is to view the investment funds as if entering by the leftmost node, "flowing" through the network, and finally leaving by the rightmost arc which collects the final wealth at the end of the investment horizon. For example, let us assume that for a given investment period the model recommends investing funds in a long USD/short AUD position. In this case part of the funds would flow from the node "Funds" to the node "Final Wealth" passing by the nodes "Long USD" and "Short AUD", respectively. The same way, investing funds in a short USD/long BEF position would be captured by the network with funds flowing from the node "Funds" to the node "Final Wealth" passing by the nodes "Short USD" and "Long BEF" respectively.

An example of an optimization model for currency allocation is given in Table 1. This is the optimization model used in the historical simulation presented below.

\section{Table 1}

Optimization model for currency allocation

\section{MODEL}

\section{SETS:}

$\star C U R$ : eleven foreign currencies $C U R=\{D E M, J P Y, B T P, F R F, B E F, D N K, S W F, S P P, I T L, C A D, A U D\}$

* POS: position in foreign exchanges $P O S=\{$ Long, Short $\}$.

* $B A S:$ positions in base currency (USD) $B A S=\{$ Cash $\} \cup P O S$.

$\star S C E$ : scenarios used $S C E=\left\{\right.$ scenario $_{1}$, scenario $_{2}, \cdots$, scenario $\left._{n}\right\}$. 


\section{Antonio Marcos Duarte Júnior}

\section{PARAMETERS:}

* $\left\{\text { return }_{I J K}\right\}_{I \in P O S, J \in C U R, K \in S C E}$ : returns under scenario $K$ for position $I$ in currency $J$.

$\star\left\{\text { upper }_{J}\right\}_{J \in C U R}:$ maximum investment allowed in currency $J$.

$\star\left\{t c_{J}\right\}_{J \in C U R}$ : transaction costs for currency $J$.

* MAR: Minimum Acceptable Return for the investment period considered.

$\star \lambda$ : penalty parameter for downside risk.

$\star C_{\text {initial }}$ : amount of funds to be invested.

$\star C_{M A R}$ : final amount of funds appreciated exactly by the investor's $M A R$.

\section{VARIABLES:}

$\star\left\{\text { allociJ }_{J}\right\}_{I \in P O S, J \in C U R}$ : allocation held for position $I$ in the foreign currency $J$.

$\star\left\{\text { domestic }_{L}\right\}_{L \in B A S}$ : allocation held for position $L$ in the base currency.

$\star\left\{\text { wealth }_{K}\right\}_{K \in S C E}$ : expected final wealth under scenario $K$.

$\star\left\{\text { risk }_{K}^{+}, \text {risk }_{\bar{K}}^{-}\right\}_{K \in S C E}$ : auxiliary variables to measure downside risk under scenario $K$.

\section{EQUATIONS:}

* Objective function to be maximized:

$$
\sum_{K \in S C E}\left(\text { wealth }_{K}-\lambda \operatorname{risk}_{\bar{K}}\right) .
$$

* Initial investment:

$$
\sum_{L \in B A S} \text { domestic }_{L}=C_{i n i t i a l} .
$$

* Allocation in foreign currencies:

$$
\text { domestic }_{L}=\sum_{J \in C U R} \frac{\text { allociJ }}{1-t c_{J}}, \forall L \in B A S, \forall I \in P O S, L \neq I \text {. }
$$


A Framework for the Active Management of a Global Currency Fund

$\star$ Expected final wealth for scenario $K$ :

$$
\text { wealth }_{K}=\sum_{I \in P O S} \sum_{J \in C U R}\left(1+\text { return }_{I J K}\right) \text { alloc }_{I J}, \quad \forall K \in S C E .
$$

* Measuring downside risk for scenario $K$ :

$$
\text { wealth }_{K}=\operatorname{risk}_{K}^{+}-\operatorname{risk}_{K}^{-}+C_{M A R}, \forall K \in S C E .
$$

* Maximum investment allowed in foreign currency $\mathrm{J}$ :

$$
\sum_{I \in P O S} \operatorname{alloc}_{I J} \leq \operatorname{upper}_{J}, \forall J \in C U R,
$$

* Nonnegative variables:

$$
\begin{aligned}
& \text { alloc }_{I J} \geq 0, \quad \forall I \in P O S, \quad \forall J \in C U R . \\
& \text { domestic }_{L} \geq 0, \quad \forall L \in B A S, \\
& \text { risk }_{K}^{+}, r i s k_{K}^{-} \geq 0, \quad \forall K \in S C E .
\end{aligned}
$$

\section{The Scenario Generation Process.}

Scenario analysis handles uncertainty in the currency allocation process by generating a large number of scenarios to capture all possible expectations of the investor. The scenario generation process can be classified as:

1) Only historical returns are used as scenarios. This is the case of historical simulations as in Grauer \& Hakansson (1986).

2) Investors expectations are combined with historical returns. This is illustrated in Black \& Litterman (1991) for the MV framework and in Koskosidis \& Duarte(1997) for the scenario-based framework.

3) Scenarios are generated without any relation to historical scenarios. 
Whichever the methodology adopted for scenario generation, each scenario must contain the expected exchange rate level for each foreign currency considered, and the interest rate implicit in the cashequivalent instrument. For example, a scenario in the case of Figure 1 is to hypothesize the AUD to weaken by $2 \%$ against the USD, the $\mathrm{BEF}$ to strengthen by $1 \%$ against the USD, and LIBOR (annual, in USD) to stay at $5 \%$.

The scenario generation was a very demanding and difficult step when using the framework presented in practice. For example, calibration involved a group of experienced research analysts, portfolio managers and traders on weekly simulations for approximately six months.

The joint impact of scenarios on the optimal currency allocation is obtained by the use of constraints and the utility function adopted to approximate the investor's risk profile (see Table 1).

\section{Incorporating Downside Risk in Utility Functions.}

Approximating the utility profile of an investor using a mathematical function is known not to be an easy task. Results in Kallberg \& Ziemba (1983) illustrate how the choice of a utility function can impact the optimal allocation obtained. We illustrate our proposal for incorporating downside risk in the currency allocation process using the most "intuitive" of all utility functions: the wealth (or linear) utility function. ${ }^{4}$ If $w$ denotes the wealth of the investor at the end of the investment horizon, the wealth utility function is given by

$$
W(w)=w
$$

That is, the investor's utility equals his wealth at the end of the investment horizon.

\footnotetext{
${ }^{4}$ Other utility functions (exponential, quadratic, etc.) can be used in this framework too.
} 
A Framework for the Active Management of a Global Currency Fund

As an extension to works such as Carino et al (1994) and Kallberg \& Ziemba (1983) we choose an utility function that:

1) It incorporates the investor's MAR.

2) It is biased towards currency allocations which do not violate (or violate by as little as possible) the investor's MAR. These two objectives can be achieved by adding to the wealth function a penalty function as depicted in Figure 2. This penalty function penalizes only those currency allocations with expected returns below the investor's MAR.

Figure 2

Utility function $=$ wealth function + penalty function

Utility Function

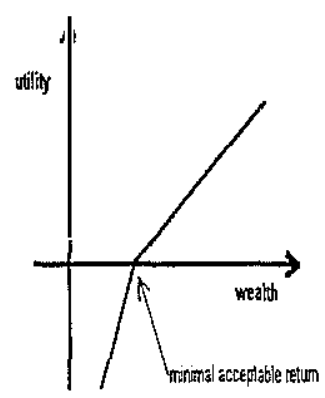

Wealth Function

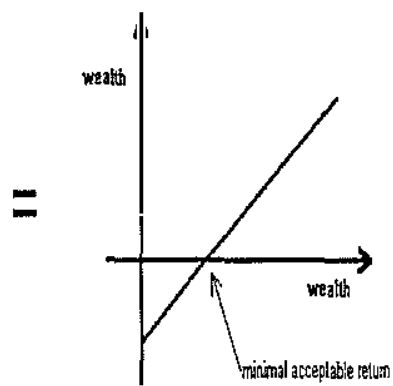

Penalty Function

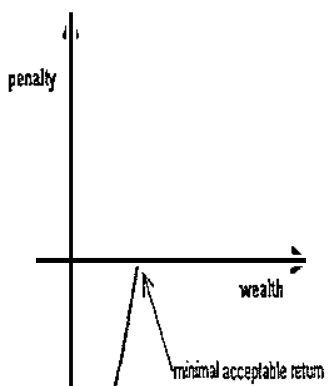

Choosing the MAR can be a difficult task. For example, Davis \& Sloan (1993) and Hammond (1993) consider the problem of defining the MAR for pension plans and endowment portfolios. In the specific case of active currency allocation it is "natural" to define the MAR as a combination of the returns of Eurodollar CDs (on the base currency, USD) plus a spread (which plays the role of a risk premium). 
For example, one MAR we use in the historical simulation presented below is LIBOR $+1 \%$.

If $w$ denotes the investor's wealth at the end of the investment horizon, and if $C_{M A R}$ denotes his final wealth if his initial investment appreciates exactly by his MAR for the investment horizon, a candidate for the penalty function is

$$
P(w)= \begin{cases}0 & \text { if } w \geq C_{M A R} \\ w-C_{M A R} & \text { if } w<C_{M A R}\end{cases}
$$

That is, for currency allocations that provide at least the investor's MAR no penalty exists, as depicted in Figure 2. On the other hand, for currency allocations that violate the investor's MAR a penalty equal to the violation is subtracted from his utility.

Combining the wealth function with the penalty function above using a parameter $\lambda$ results in

$U(w)=W(w)+\lambda P(w)= \begin{cases}w & \text { if } w \geq C_{M A R} \\ w+. \lambda\left(w-C_{M A R}\right) & \text { if } w<C_{M A R}\end{cases}$

Large values of $\lambda$ penalize more severely currency allocations with expected returns below the MAR. Since choosing a value for $\lambda$ is a investor-dependent problem, we recommend doing a historical simulation for different values of this parameters to better understand its impact on the final currency allocation. The utility function in (3) is used in the historical simulation presented below.

\section{Historical Simulation.}

In order to illustrate the use of the framework, a historical simulation covering the years of 1994, 1995 and 1996 is presented in this section. Eleven foreign currencies were used: Australian dollar, Belgian franc, British pound, Canadian dollar, Danish krone, French 
franc, German mark, Italian lira, Japanese yen, Spanish peseta and Swiss franc. It was assumed that on the first Monday of 1994 an optimal currency allocation was obtained using the mathematical model given in Table 1. The historical returns of the preceding twentysix weeks (half year) were used as equally probable scenarios. This currency allocation was held for exactly one week, and its realized returns computed. This procedure was repeated again for the week starting on the second Monday of 1994, and so on until the last Monday of 1996. The weekly realized returns obtained were used to compute annual realized returns and volatilities to access the expost performance of the methodology in the historical simulation. The only exogenous constraints imposed to the currency allocation model required the investment in each foreign currency not to exceed $25 \%$ of the total amount of funds available for investing. No leverage was allowed. ${ }^{5}$ Several levels for the investor's MAR were used, and the penalty parameter in Equation (3) was set to $\lambda=4$. Finally, seven-day Eurodollar CDs were used as cash-equivalent assets.

As an illustration, some results are depicted in Figure 3. In this plot the annual realized returns and volatilities of eleven positions in foreign exchange markets and cash-equivalents instruments are provided. ${ }^{6}$ Also, the annual realized return and volatilities obtained for four levels of the MAR (LIBOR+0\%, LIBOR+1\%, LIBOR+2\% and LIBOR $+3 \%$ ) and a naïve strategy that invested equally in the eleven currencies (taking the positions in Figure 3) are provided. We can observe that the four-point approximation to the ex-post efficient frontier (four black squares) dominates the naïve investment strategy and the eleven currency positions depicted in Figure 3.

\footnotetext{
${ }^{5}$ That is, the summation of the absolute value of all positions (long and short, before computing transaction costs) in USD equals the initial amount available for investing.

${ }^{6}$ For each foreign currency there are two possible positions with respect to USD: short the currency/long USD or long the currency/short USD. Although the two positions have equal volatilities, their returns are symmetric numbers. For example, the realized return of the position long DEM/short USD was $3.3 \%$ for the period of simulation, while the realized return of the position short DEM/long USD was $-3.3 \%$. We depict in Figure 3 only those positions with positive realized returns for the period of simulation.
} 
Figure 3

Realized returns and volatilities of the historical simulation

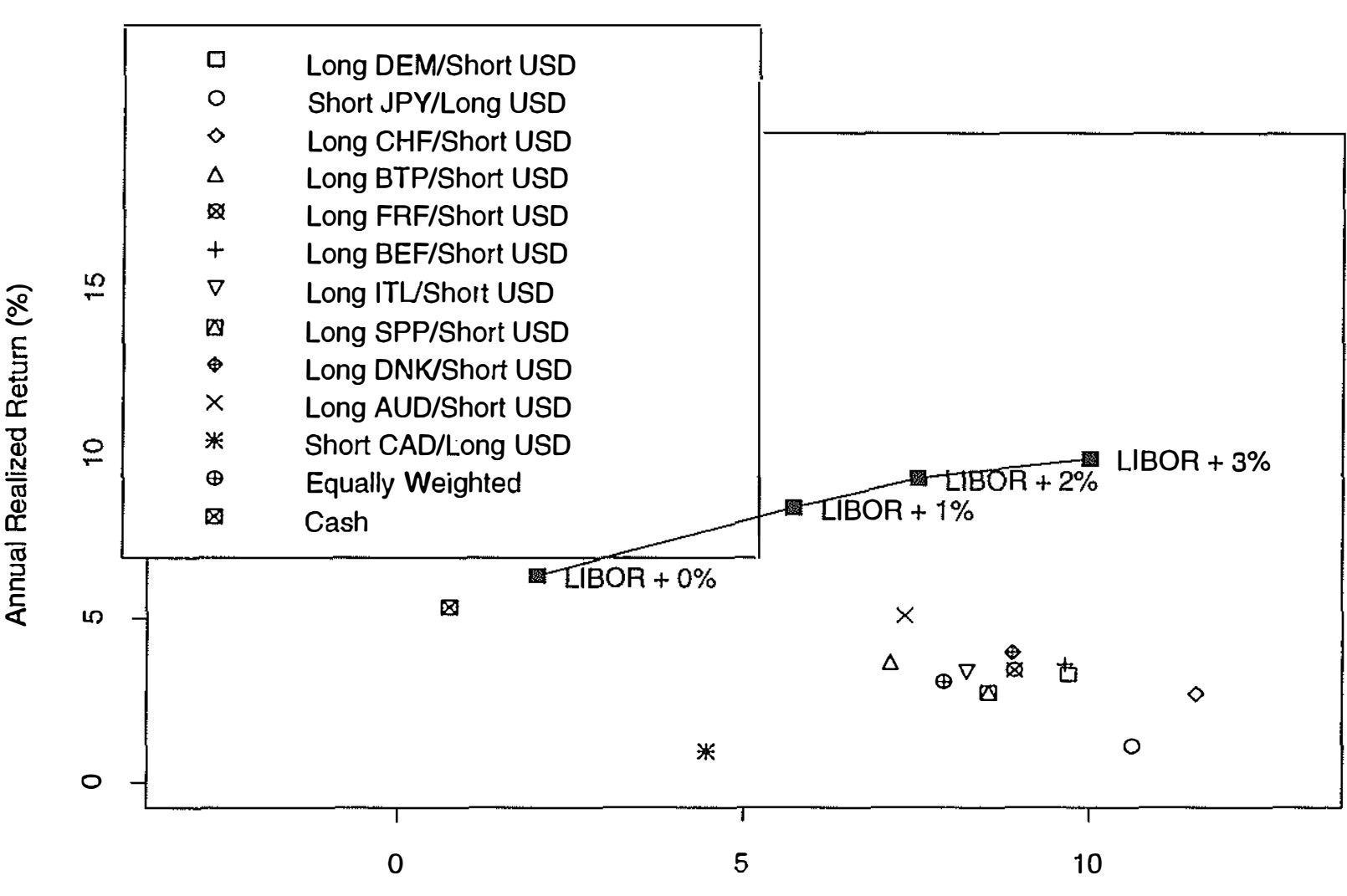


However, the proposed methodology was not designed to be used with historical scenarios. It was designed to be used for the active management of a global currency fund. In this case, the portfolio manager must provide his future expectations by inputting scenarios in the mathematical model given in Table 1, as well as defining his MAR and penalty parameter $\lambda$. Historical simulations are important when calibrating the proposed methodology for the specific needs of a portfolio manager. A combination of the methodology presented here, with that presented in Koskosidis \& Duarte (1997), was used to manage more than US $\$ 400$ million in a global currency fund at the end of 1994.

\section{Extensions to Multiperiod Investment Analysis.}

The framework presented and tested in the preceding sections can be extended to cover multiperiod investments. Multiperiod models are important because they allow the investor to look further into the future, instead of relying on the "myopic" view of uniperiod models (Carino et al (1993), Crum et al (1979) and Mulvey \& Vladimirou (1989)). Although the framework becomes more complex as the investment horizon widens, the graphical representation of the currency allocation methodology as a network simplifies the task of understanding the necessary modifications. Figure 4 depicts the simplest case possible of a multiperiod model for currency allocation: a two-period network with only one foreign currency (Spanish peseta, SPP).

The four major modifications required to transform a singleperiod approach into a multiperiod approach are:

1) The topology of the one-period network must be replicated for all investment periods covered by the investment horizon.

2) The approach must allow investors to take positions covering any combination of investment periods. This is exemplified by the two longest arcs in Figure 4. These arcs allow the investor to take positions in the beginning of the first investment period that will last until the end of the second investment period. 


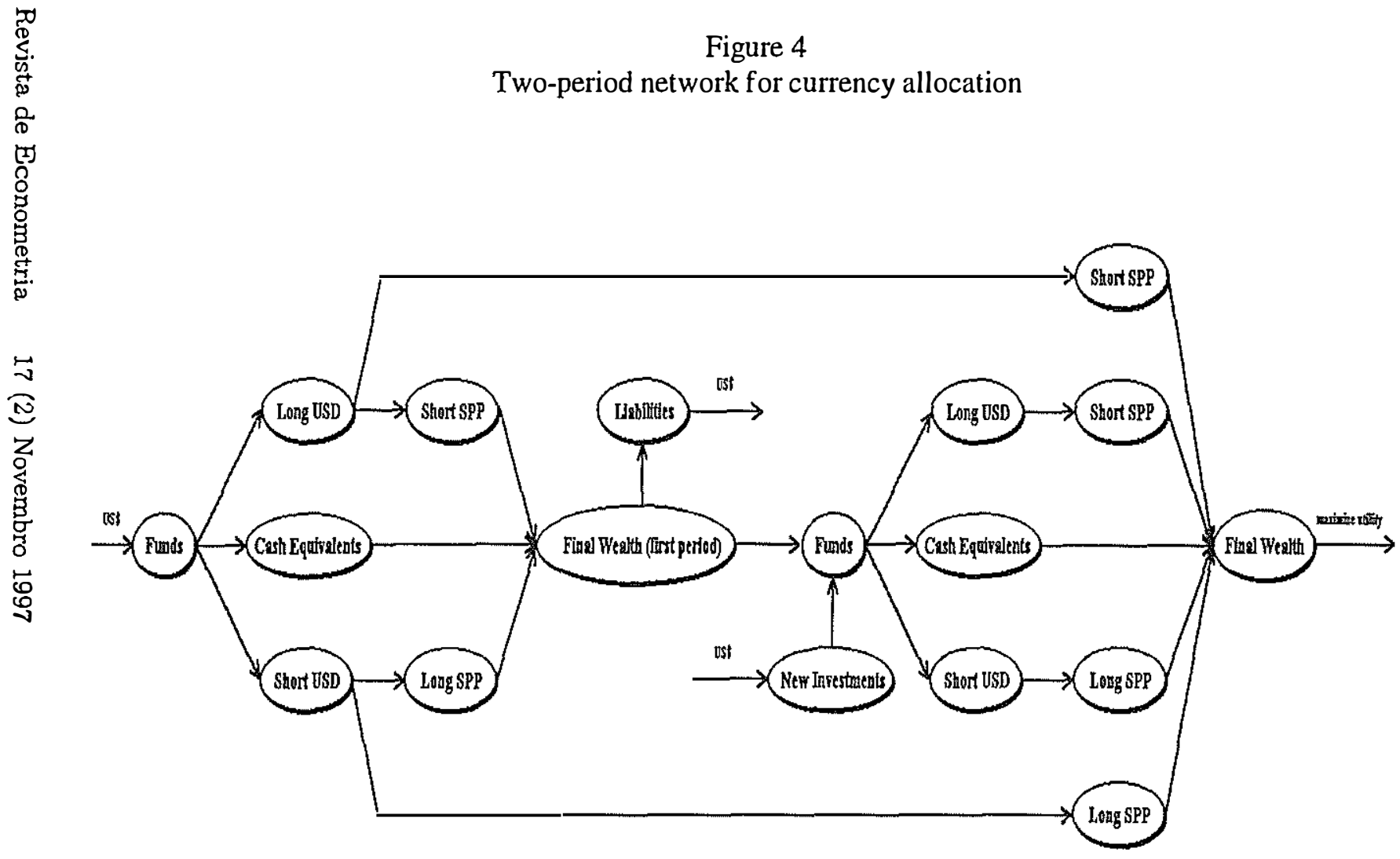


A Framework for the Active Management of a Global Currency Fund

3) New investments and previously assumed commitments must be incorporated in the methodology. This can be achieved by introducing nodes in the network named "New Investments" and "Liabilities". These nodes allow funds to leave or enter the investment process at the end of each investment period.

4) A utility function that recognizes the time value of money must be used. For example, it is possible to modify the utility function so that it optimizes not the utility at the end of the investment horizon, but rather the present value of all funds leaving the network at the end of each investment period.

The scenario generation process is perhaps the most difficult step when using a multiperiod methodology for fund management in practice. In this case, the investor must forecast liabilities, new investments, forward rates and the exchange rate level of all currencies at the end of all investment periods. This is a herculean task from the operational point of view.

\section{Conclusion.}

A framework for the management of a global currency fund was presented. Important operational aspects for practitioners were explained in a very intuitive way. The results of a historical simulation and extensions for multiperiod investments were presented and analyzed. The rigorous mathematical formulation of the optimization model used in the historical simulation was provided.

The framework proposed relies on scenario analysis and downside risk. This proposal shows a modeling flexibility which makes it a better choice when compared to alternatives based on Markowitz's Mean-Variance framework. The framework proposed can be adapted to the currency hedge and currency overlay problems in order to obtain better approaches than those available nowadays (based on Markowitz's Mean-Variance framework). 
Finally, the use of the framework presented is not limited to fund management. For example, it can be used as a strategic tool to understand the mechanics of international currency markets. It can also help understanding a set of scenarios for international currency markets. A third possible use is to provide a compromise solution for conflicting views of different global currency strategists.

Submetido em Junho 1997. Revisado em Março de 1998.

\section{References}

Black, F. \& Litterman, R. 1991. "Asset allocation: combining investor views with market expectations." Journal of Fixed Income 1:7-18.

Braccia, J.A. 1995. "An analysis of currency overlays for U.S. pension plans." Journal of Portfolio Management 22:88-93.

Carino, D.R.; Kent, T.; Myers, D.H.; Stacy, C.; Sylvanus, M.; Turner, A.; Watanabe, K. \& Ziemba, W.T. 1994. "The RussellYasuda Kasai model: an asset-liability model for a japanese insurance company using multistage stochastic programming." Interfaces 24:29-49.

Chamberlain, G. 1993. "A characterization of the distributions that imply the mean-variance utility functions." Journal of Economic Theory 29:185-201.

Chopra, V.K. 1993. "Improving optimization." Journal of Investing 2:51-59.

Crum, R.L.; Klingman, D.D. \& Tavis, L.A. 1979. "Implementation of large-scale financial planning models: solution efficient transformations." Journal of Financial and Quantitative Analysis 13:87-102.

Davis, R.M. \& Sloan, M.T. 1993. "Pension plans: a risk management perspective." Journal of Investing 2:17-23. 
A Framework for the Active Management of a Global Currency Fund

Duarte Jr., A.M. 1994. "A comparative study of downside risk and volatility in asset allocation." Investigación Operativa 4:213228.

Duarte Jr., A.M. 1997. "Model risk and risk management." Derivatives Quarterly 3:60-72.

Epstein, L. 1985. "Decreasing risk aversion and mean-variance analysis." Econometrica 53:945-962.

Gardner, G.W. \& Wuilloud, T. 1995. "Currency risk in international portfolios: how satisfying is optimal hedging?" Journal of Portfolio Management 21:59-67.

Glen, J. \& Jorion, P. 1993. "Currency hedging for international portfolios." Journal of Finance 48:1865-1886.

Grauer, R.R. \& Hakanson, N.H. 1986. "A half century of returns on levered and unlevered portfolios of stocks, bonds and bills, with and without small stocks." Journal of Business 59:287-319.

Hammond, D.R. 1993. "Risk management approaches in endowment portfolios in the 1990's." Journal of Investing 2:24-29.

Harlow, W.V. 1993. "Asset allocation in a downside risk framework." Financial Analysts Journal 49:14-26.

Huang, C. \& Litzemberger, R. 1988. "Foundations for Financial Economics." Prentice Hall: Englewood Cliffs.

Jorion, P. 1994. "Mean-variance analysis of currency overlays." Financial Analysts Journal 50:41-50.

Kallberg, J.G. \& Ziemba, W.T. 1983. "Comparison of alternative utility functions in portfolio selection problems." Management Science 29:1257-1276.

Koskosidis, Y.K. \& Duarte Jr, A.M. 1997. "A scenario-based approach for active asset allocation." Journal of Portfolio Management 23: 74-85. 
Lewis, A.L. 1990. "Semivariance and the performance of portfolios with options." Financial Analysts Journal 46:67-76.

Marmer, H.S. \& Ng, F.K.L. 1993. "Mean-semivariance analysis of option-based strategies: a total asset mix perspective." Financial Analysts Journal 49:47-54.

Michaud, R.O. 1989. "The Markowitz optimization enigma: is 'optimized' optimal?" Financial Analysts Journal 45:31-42.

Mulvey, J.M. \& Vladimirou, H. 1989. "Stochastic network optimization models for investment planning." Annals of Operations Research 20:187-217.

Nemhauser, G.L.; Rinnooy, A.H.G. \& Todd, M.J. (eds.) 1989. Operations Research and Management Science: Optimization. Amsterdan, Holland: North Holland.

Sorensen, E.H.; Mezrich, J.J. \& Thadani, D.N. 1993. "Currency hedging through portfolio optimization." Journal of Portfolio Management 19:27-35.

Sortino, F.A. \& Van der Meer, R. "Downside risk." Journal of Portfolio Management 17:37-43. 
